\title{
BMJ Open Fatigue and recovery among Malaysian doctors: the role of work-related activities during non-work time
}

\author{
Mohd Fadhli Mohd Fauzi (10 , ${ }^{1,2}$ Hanizah Mohd Yusoff, ${ }^{1}$ Nur Adibah Mat Saruan, ${ }^{1,2}$ \\ Rosnawati Muhamad Robat, ${ }^{2}$ Mohd Rizal Abdul Manaf, ${ }^{1}$ Maisarah Ghazali ${ }^{1,2}$
}

To cite: Mohd Fauzi MF, Mohd Yusoff H, Mat Saruan NA, et al. Fatigue and recovery among Malaysian doctors: the role of work-related activities during non-work time. BMJ Open 2020;10:e036849. doi:10.1136/ bmjopen-2020-036849

- Prepublication history for this paper is available online. To view these files, please visit the journal online (http://dx.doi org/10.1136/bmjopen-2020036849).

MFMF and HMY are joint first authors.

Received 07 January 2020

Revised 15 August 2020

Accepted 25 August 2020

Check for updates

(C) Author(s) (or their employer(s)) 2020. Re-use permitted under CC BY-NC. No commercial re-use. See rights and permissions. Published by BMJ.

${ }^{1}$ Department of Community Health, Faculty of Medicine, Universiti Kebangsaan Malaysia, Cheras, Malaysia

${ }^{2}$ Occupational and Environmental Health Unit, Selangor State Health Department, Shah Alam, Malaysia

Correspondence to Dr Hanizah Mohd Yusoff; drhanie@ppukm.ukm.edu.my

\section{ABSTRACT}

Objectives This paper aims to estimate the level of acute fatigue, chronic fatigue and intershift recovery among doctors working at public hospitals in Malaysia and determine their inter-relationship and their association with work-related activities during non-work time.

Design Cross-sectional.

Setting Seven core clinical disciplines from seven tertiary public hospitals in Malaysia.

Participants Study was conducted among 330 randomlysampled doctors. Response rate was $80.61 \%(n=266)$.

Results The mean score of acute fatigue, chronic fatigue and intershift recovery were $68.51(\mathrm{SD}=16.549), 54.60$ $(S D=21.259)$ and $37.29(S D=19.540)$, respectively. All these scores were out of 100 points each. Acute and chronic fatigue were correlated $(r=0.663)$, and both were negatively correlated with intershift recovery ( $r=-0.704$ and $r=-0.670$, respectively). Among the workrelated activities done during non-work time, work-related ruminations dominated both the more frequent activities and the association with poorer fatigue and recovery outcomes. Rumination on being scolded/violated was found to be positively associated with both acute fatigue (adjusted regression coefficient $($ Adj..$b)=2.190,95 \%$ $\mathrm{Cl}=1.139$ to 3.240 ) and chronic fatigue (Adj. $b=5.089$, $95 \% \mathrm{Cl}=3.876$ to 6.303 ), and negatively associated with recovery (Adj. $b=-3.316,95 \% \mathrm{Cl}=-4.516$ to -2.117 ). Doing work task at workplace or attending extra workrelated activities such as locum and attending training were found to have negative associations with fatigue and positive associations with recovery. Nevertheless, doing work-related activities at home was positively associated with acute fatigue. In terms of communication, it was found that face-to-face conversation with partner did associate with higher recovery but virtual conversation with partner associated with higher acute fatigue and lower recovery.

Conclusions Work-related ruminations during non-work time were common and associated with poor fatigue and recovery outcomes while overt work activities done at workplace during non-work time were associated with better fatigue and recovery levels. There is a need for future studies with design that allow causal inference to address these relationships.

\section{INTRODUCTION}

Fatigue, a suboptimal psychophysiological condition caused by exertion, is closely

\section{Strengths and limitations of this study}

Multicentre study involving seven core clinical disciplines from seven tertiary public hospitals.

- Multiple dependant variables which include acute fatigue, chronic fatigue and intershift recovery which are rarely explored simultaneously among doctors.

- Cover multiple independent variables which includes the rarely explored work-related activities during non-work time among doctors that are potentially associated with acute fatigue, chronic fatigue and intershift recovery.

- This study specifically involves doctors working at tertiary public hospitals and excludes house officers and specialists; therefore, the findings cannot be widely generalised to house officers, specialists and doctors in non-hospital settings.

- This is a cross-sectional study; thus it is unable to infer causation.

related to recovery, in which, in the absence of sufficient recovery, acute fatigue may commence into chronic fatigue. ${ }^{1-6}$ In line with conservation of resources (COR) theory, fatigue is a manifestation of adverse psychological condition following loss of energy resources or a lack of energy resources replacement. ${ }^{7-9}$ Acute fatigue is a normal adaptive response to work activity that is reversible, task-specific and disappears after a period of rest. ${ }^{4}$ However, this adaptive response is dependent on adequate recovery during intershift, or non-work, period. ${ }^{56}$ Inadequate intershift recovery of acute fatigue may begin a cycle of accumulated unrecovered fatigue which progresses to the chronic maladaptive fatigue $^{5610}$ which is not task-specific ${ }^{4}$ and cannot be alleviated by rest alone. ${ }^{11}$

The prevalence of fatigue among doctors is significant. Multiple studies among doctors found that prevalence of fatigue range from $28 \%$ to $91 \% .^{12-18}$ The majority of them were experiencing high and frequent fatigue ${ }^{17} 18$ with low and moderate intershift recovery. ${ }^{19}$ These findings are not surprising as a doctor's 
duty, especially in the hospital setting, is commonly associated with long work hours, frequent on-call duty, inadequate recovery time and night shift work. ${ }^{12} 15-172021$ The non-work intershift period, which has been rarely explored, is equally critical in mitigating fatigue issue so that the doctor will arrive at the next working day with no residual fatigue. ${ }^{2}$

The non-work intershift period should be free from work-related activities to foster recovery, ${ }^{22}$ or otherwise recovery will be hindered. ${ }^{23}$ The work-related activities during non-work intershift period can be in the form of psychological rumination, ${ }^{24-26}$ task $^{23}$ or communication. ${ }^{27}$ Work-related ruminative thoughts include the rumination on being violated at work ${ }^{26}$ which is not uncommon among doctors, ${ }^{28-30}$ self-wrongdoing at workplace ${ }^{31}$ and other workplace stressors. ${ }^{24}$ Being violated at the workplace is known to be associated with rumination and fatigue. ${ }^{32-34}$ Other risk factors of fatigue include pressures related to unresolved or forthcoming work, additional responsibilities (such as doing locum), specific work requirements (such as telephone consultations or handling work-related social media) and technologyassisted work-related task. ${ }^{20} 273536$ However, the role of work-related activities during non-work time in fatigue and recovery among doctors has rarely been explored.

Fatigue, which is closely related with poor recovery, ${ }^{1-6}$ is harmful as it may compromise safety of the doctors such as through commuting accidents ${ }^{37}$ and needlestick injury. ${ }^{38}$ Additionally, fatigue doctors may jeopardise patients' safety $^{40}$ through diagnostic errors, ${ }^{41}$ medical error, ${ }^{42}$ clinical error ${ }^{43}$ and inappropriate treatment. ${ }^{44}$ Furthermore, studies among doctors found that fatigue can affect work and organisation such as less enjoyment in work ${ }^{18}$ and high turnover intention. ${ }^{13}$ Other consequences include adverse health and well-being, work-life dissatisfaction, low quality of life, job dissatisfaction and poor skill performance. ${ }^{40}$

Fatigue among doctors in Malaysia has just recently gained national attention. ${ }^{45}{ }^{46}$ Long work hours and lack of recovery opportunities have always been blamed for the fatigue suffered by doctors. ${ }^{45}$ Multiple health-related and road safety-related organisations are demanding the government for actions such as an establishment of a safe work hours law to address this issue. ${ }^{45}{ }^{47}$ However, there is limited research on fatigue and recovery among doctors, particularly in Malaysia. The scientific information that is needed in order to develop evidence-based local legislation and policy, is therefore currently insufficient.

In Malaysia's healthcare setting, doctors, which includes house officers, medical officers and specialists, make a large portion of the health workforce, ${ }^{48}$ especially in the core clinical disciplines, which include internal medicine, surgery, orthopaedic, paediatric, obstetrics and gynaecology, anaesthesiology and psychiatry. ${ }^{48}$ The current practice in most core clinical disciplines at public hospitals in Malaysia is to have on-call duties from 08:00 hours to 17:00 hours of the next day. ${ }^{49}$ After working continuously for 33 hours and finishing on-call duties at
17:00 hours, most of them are required to come back to work at 08:00 hours on the following day, corresponding to intershift duration of just 15 hours. ${ }^{45} 49$ However, little is known on the work-related activities being done during this non-work intershift period by doctors in Malaysia, and their associations with fatigue and recovery.

Despite numerous studies related to work hours and fatigue ${ }^{12-21}$ there is limited study specifically on acute fatigue, chronic fatigue and intershift recovery as well as their association with work-related activities during non-work time among doctors. To date, no similar study has been done in Malaysia. Therefore, this study aims were to; (1) estimate the level of acute fatigue, chronic fatigue and intershift recovery among doctors working at public hospitals in Malaysia, (2) determine their interrelationship and (3) determine their associations with work-related activities during non-work time.

\section{METHODOLOGY}

\section{Study location}

This study was conducted at all seven tertiary public hospitals located in the state of Selangor, Malaysia. Selangor is one of the most populated state with $20 \%$ of total Malaysian population.

\section{Study design and sampling}

A cross-sectional survey was conducted among randomlyselected doctors from seven core clinical disciplines which practised on-call system, that is, internal medicine, surgery, orthopaedic, paediatric, obstetrics and gynaecology, anaesthesiology and psychiatry at these hospitals.

Our target population was non-resident and nonspecialist doctors who worked at tertiary public hospitals in Malaysia. All seven tertiary public hospitals in the state of Selangor were chosen as the sample population to represent tertiary public hospitals in Malaysia. These hospitals represent $20 \%$ of all tertiary public hospitals in Malaysia. On the other hand, the sample population represents almost $25 \%$ of target population. The inclusion criteria were Malaysian doctors who are permanently (not temporary nor contractual) appointed under civil service sector and has been working at current workplace for at least 1 month. The exclusion criteria are house officers, specialists and postgraduate candidates, and those medically diagnosed as, or on treatment for, sleep disorder or mental illness. Sampling frame was obtained from the office of respective department at each hospital. We conducted probabilistic simple random sampling procedure by combining all the names into one master list, followed by random selection using Microsoft Excel to select the number of participants based on the calculated sample size.

Based on the calculated sample size of one-group analytical study with $95 \%$ CI, power of 0.80 and expected correlation coefficient of $0.16,,^{50} 304$ participants were required. Alternatively, based on calculated sample size with $95 \%$ CI, power of 0.80 and fatigue prevalence of 
$0.84,{ }^{15} 0.91^{16}$ and $0.79,{ }^{17}$ we required 207,126 and 255 participants. Hence, 330 questionnaires were randomly distributed to participants from seven core clinical disciplines at seven tertiary hospitals. These 330 randomlyselected participants represent about $15 \%$ of total sample population.

\section{Study instruments}

Data was collected using a specially designed questionnaire. It was designed through discussion among authors. It contained sociodemographic information, occupational-related information, self-constructed 7-point Likert-scale work-related activities during non-work hours and 15-items Occupational Fatigue/Exhaustion Recovery (OFER-15) scale. ${ }^{6}$ Sociodemographic and occupationalrelated information were collected to describe the participants characteristic and act as controlled variables. On the other hand, work-related activities during non-work hours scale and OFER-15 act as independent and dependent variables, respectively. In general, the coverage and relevance of the contents were validated by experts in occupational health from both the academic (university) and civil service sectors (state health department). The overall questionnaire was pretested to ensure face validity. It was then piloted among 30 participants to assess reliability and reassess face validity. The Cronbach's alpha for acute fatigue, chronic fatigue and intershift recovery were $0.737,0.828$ and 0.704 , respectively.

OFER-15 is a validated questionnaire containing three subscales, that is, acute fatigue, chronic fatigue and intershift recovery. ${ }^{6}$ Each subscale consists of five items with 7-point Likert scale scoring from 0 (strongly disagree) to 6 (strongly agree). Each subscale sums the five items; thus, each subscale may produce score of 0 to 30 . The total score for each subscale was divided by 30 , followed by multiplication of 100 to produce comparable score of 0 to $100 .{ }^{6}$ Higher scores for acute and chronic fatigue indicate higher acute and chronic fatigue, respectively, whereas higher scores for intershift recovery reflect higher intershift recovery.

The work-related activities during non-work hours scale is a self-constructed 23-items 7-point Likert-scale. The points are 0 (never), 1 (less than once per month), 2 (once per month), 3 (more than once per month), 4 (once a week), 5 (more than once a week) and 6 (daily). The list of activities was developed through interview with source population, authors' experiences, expert opinion and literature review. Fourteen medical doctors, or two from each core clinical disciplines, were purposively approached to list and describe any work-related activities during non-work time as many as possible. Three occupational health experts were also purposively approached and given similar task. All authors, who are also medical doctors, share own experiences throughout working life as medical doctors among themselves, and added the findings into the list. We also employed scoping literature search specifically on type of activities during nonwork time being done by general employees and suited them into medical doctors' career. The list was finally combined into one master list. Literature reviews revealed items related to rumination, unfinished task, work-related conversation with multiple parties and technologyassisted work-related communication during non-work time. ${ }^{2023-2732-36}$ Interview with target population revealed items, apart from findings from literature reviews, related to extended unpaid working hours for training, meeting, discussion and clients-related task, as well as instruction received through technology-assisted communication devices. Others included locum and handling organisation website or social media. Expert opinions involving occupational health physician consensually endorsed all these generated items. The final 23-item inventory contained work-related activities that covers different type of activities (ie, rumination, task, communication), mediums (ie, psychological, physical, virtual) and interaction groups (ie, superior, colleague, patients/clients, partners, self).

\section{Data analysis}

Responses from questionnaires were categorised and coded. Data were analysed by using SPSSV.21. Univariable data were analysed and presented descriptively as mean and SD or frequencies and percentages. Bivariable data were analysed by using simple linear regression. Multiple linear regression analysis was subsequently conducted to identify factors associated with acute fatigue, chronic fatigue and intershift recovery. All independent variables, consisting of sociodemographic profile, occupational profile, work-related activities during non-work time and work-home commuting profile, were initially included and elimination was done by stepwise method. Data were presented as adjusted regression coefficient (Adj.b), 95\% $\mathrm{CI}$ and $\mathrm{p}$ value. Significant level was set at $\mathrm{p}<0.05$.

\section{Patient and public involvement statement}

PPI representatives partially worked with us to refine the research question on work-related activities during nonwork time; however, it was difficult to involve PPI in other areas of the study design due to data protection restrictions. PPI representatives will assist us in dissemination of study information to their peers.

\section{RESULTS}

We received 266 completed questionnaires out of the 330 questionnaires distributed. Thus, the response rate was $80.61 \%$

\section{Participants' profile}

Table 1 described participants profile. Majority were women with mean age of $31.04(\mathrm{SD}=3.357)$ years. They work in average of $4.31(\mathrm{SD}=2.865)$ years as doctors. All of them used WhatsApp as work-related communication technology medium, and some used dual medium. Interestingly, $86.5 \%$ of participants perceived that work-related communication medium push them to do, or to ruminate on, work-related matters during non-work time. 
Table 1 Participants characteristic $(n=266)$

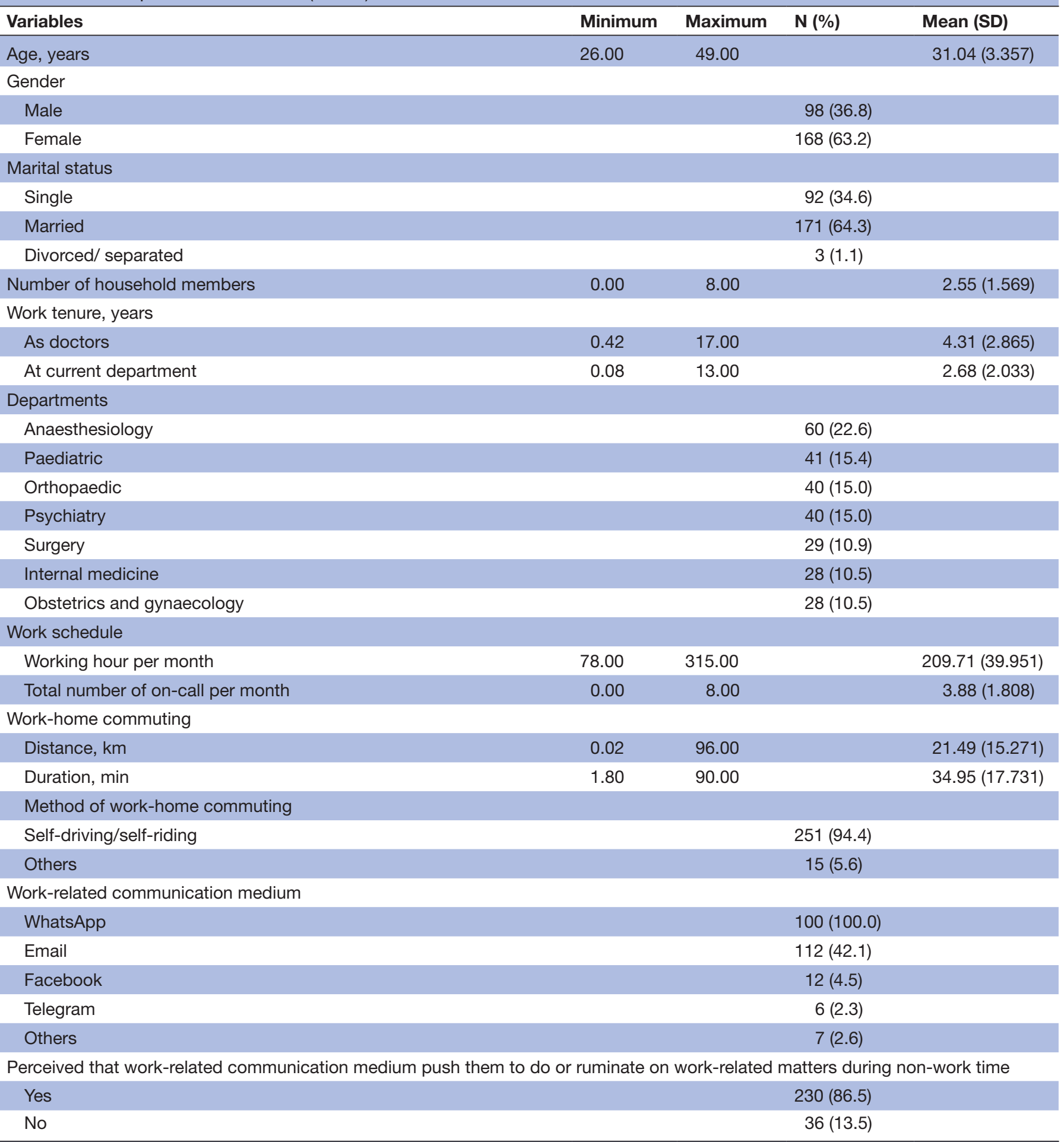

\section{Work-related activities during non-work time}

Table 2 listed the 23 work-related activities during nonwork time. Generally, work-related rumination dominated the more frequent activities done by the doctors. In contrast, task-related activities particularly locums and meetings were the least frequently done work-related activities during non-work time.

There were six work-related activities during non-work time occurring at least once a week. They are rumination on patients/clients $(\mathrm{M}=4.84, \mathrm{SD}=1.699)$, doing work task at workplace $(\mathrm{M}=4.73, \mathrm{SD}=1.817)$, informal conversation with colleague virtually $(\mathrm{M}=4.46, \mathrm{SD}=1.753)$, physical communication with patients/clients $(\mathrm{M}=4.38$, $\mathrm{SD}=2.381)$, rumination on upcoming work $(\mathrm{M}=4.18$, $\mathrm{SD}=2.016)$ and rumination on unfinished task $(\mathrm{M}=4.16$, $\mathrm{SD}=1.959)$. Even though most of the task-related activities were less likely to be done by the doctors during their non-work time, doing work task at workplace was very 
Table 2 Work-related activities during non-work time $(n=266)$

\begin{tabular}{|c|c|c|}
\hline Work-related activities during non-work time & Types & Mean (SD)* \\
\hline 1. Rumination on patient/clients & Rumination & $4.84(1.699)$ \\
\hline 2. Doing work task at workplace & Task & $4.73(1.817)$ \\
\hline 4. Physical communication with patients/clients & Communication & $4.38(2.381)$ \\
\hline 5. Rumination on upcoming work & Rumination & $4.18(2.016)$ \\
\hline 7. Informal conversation with colleague physically & Communication & $3.84(2.117)$ \\
\hline 8. Rumination on self-wrongdoing & Rumination & $3.66(1.911)$ \\
\hline 9. Physical conversation with partner & Communication & $3.48(2.389)$ \\
\hline 10. Rumination on being scolded/violated & Rumination & $3.31(1.976)$ \\
\hline 11. Virtual conversation with partner & Communication & $2.94(2.402)$ \\
\hline 14. Instruction from superior via phone call & Communication & $2.71(1.896)$ \\
\hline 15. Physical conversation with parent & Communication & $2.58(1.947)$ \\
\hline 16. Virtual conversation with parent & Communication & $2.01(2.093)$ \\
\hline 17. Handling email/website/social media & Task & $1.79(1.924)$ \\
\hline 18. Attending work-related meeting physically at workplace & Task & $1.63(1.422)$ \\
\hline 19. Attending work-related training & Task & $1.33(1.424)$ \\
\hline 20. Virtual communication with patients/clients & Communication & $0.95(1.541)$ \\
\hline 21. Attending work-related meeting virtually & Task & $0.77(1.439)$ \\
\hline 22. Locum at private health facilities & Task & $0.81(1.463)$ \\
\hline
\end{tabular}

*Higher mean refers to higher frequency.

common that it was the second occurring activities among the list being studied. Doing work task at home $(M=2.74$, $\mathrm{SD}=1.756$ ) did occur among these doctors but at a much less frequency. Receiving instruction from superior via text message/email or via phone call were also found to occur once per month $(\mathrm{M}=2.76, \mathrm{SD}=1.830$ and $\mathrm{M}=2.71$, $\mathrm{SD}=1.896$, respectively).

Level and correlation of acute fatigue, chronic fatigue and intershift recovery

Table 3 showed mean level of acute fatigue, chronic fatigue and intershift recovery, and the correlation among them. The mean score of acute fatigue, chronic fatigue and intershift recovery were $68.51(\mathrm{SD}=16.549), 54.60$
$(\mathrm{SD}=21.259)$ and $37.29(\mathrm{SD}=19.540)$, respectively. All these scores were out of 100 points each. Acute fatigue was moderately and positively correlated with chronic fatigue, and both were moderately and negatively correlated with intershift recovery.

Factors associated with acute fatigue, chronic fatigue and intershift recovery

Table 4 demonstrated the factors associated with acute fatigue, chronic fatigue and intershift recovery. Age, gender, marital status and monthly work hours did not associate with fatigue and recovery. There were significant linear relationships between seven independent variables and acute fatigue $\left(\mathrm{R}^{2}=0.32\right)$, five independent variables

Table 3 Level of acute fatigue, chronic fatigue and intershift recovery and correlation among them $(n=266)$

\begin{tabular}{lllcc}
\hline & & \multicolumn{2}{l}{ Pearson correlation } & \\
\cline { 2 - 5 } Variables & Mean (SD) & Acute fatigue & Chronic fatigue & Intershift recovery \\
\hline Acute fatigue & $68.51(16.549)$ & 1 & $0.663^{*}$ & $-0.704^{*}$ \\
Chronic fatigue & $54.60(21.259)$ & $0.663^{*}$ & 1 & $-0.670^{*}$ \\
Intershift recovery & $37.29(19.540)$ & $-0.704^{*}$ & $-0.670^{*}$ & 1 \\
\hline
\end{tabular}

${ }^{*} p<0.05$ 


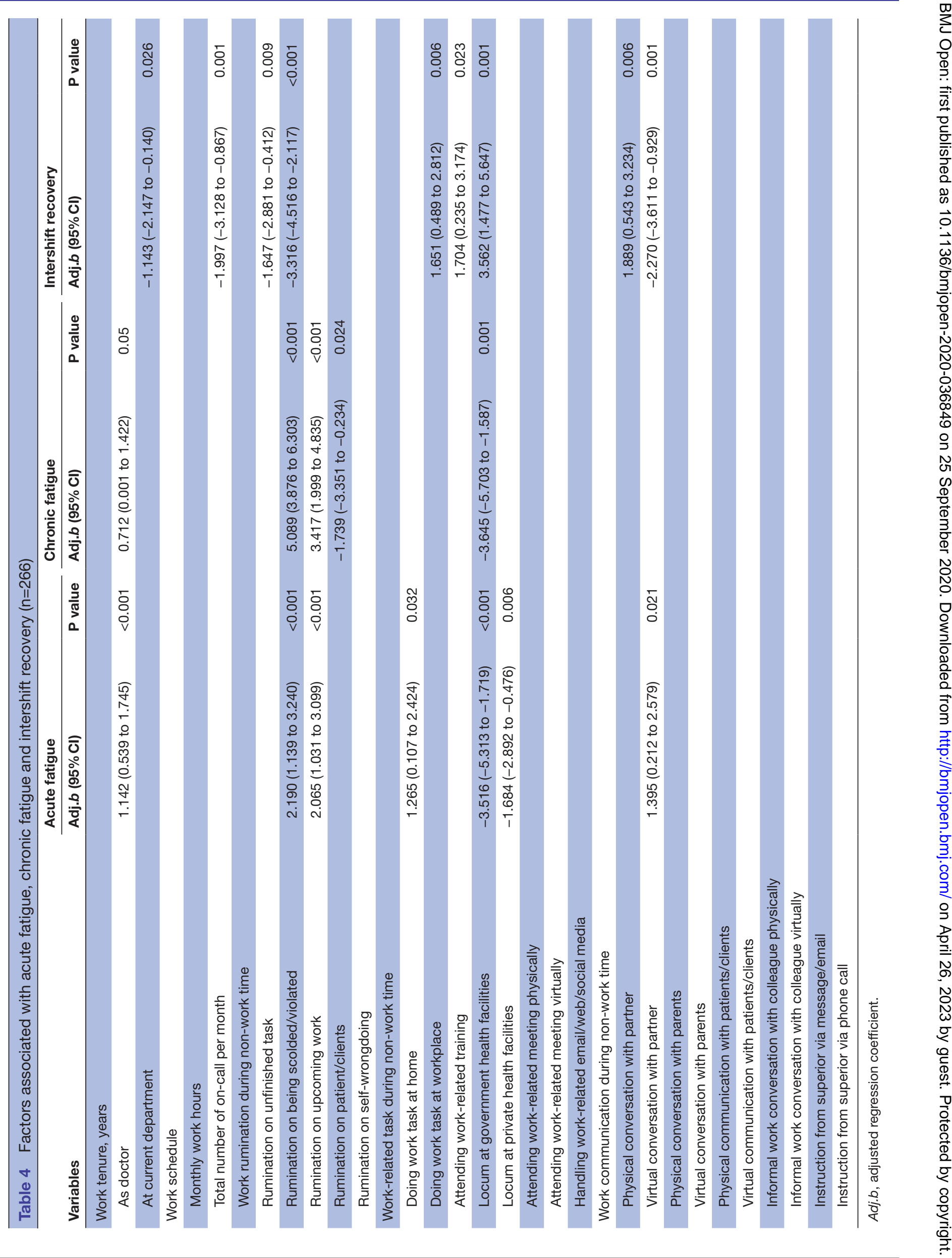


and chronic fatigue $\left(R^{2}=0.40\right)$ and nine independent variables and intershift recovery $\left(R^{2}=0.28\right)$.

All the three types of work-related activities had factors that were associated with dependant variables. With regards to the work-related ruminations that were done during non-work time, all except one (rumination on self-wrongdoing) of the work-related ruminations found to have significant associations with at least one of the dependent variables. Rumination on being scolded/ violated was found to be associated with higher level of both acute fatigue (Adj. $b=2.190,95 \% \mathrm{CI}=1.139$ to 3.240) and chronic fatigue (Adj. $b=5.089,95 \% \mathrm{CI}=3.876$ to 6.303 ) and lower level of recovery (Adj. $b=-3.316,95 \% \mathrm{CI}=-4.516$ to -2.117). Rumination on upcoming work was associated with higher acute fatigue (Adj. $b=2.065,95 \% \mathrm{CI}=1.031$ to 3.099) and chronic fatigue (Adj. $b=3.417,95 \%$ CI=1.999 to 4.835 ), while rumination of unfinished task was associated with lower recovery (Adj. $b=-1.647,95 \% \mathrm{CI}=-2.881$ to -0.412 ). In contrast, rumination on patients/clients was the only work-related rumination that was found to be associated with lower level of chronic fatigue (Adj. $b=-1.739,95 \% \mathrm{CI}=-3.351$ to -0.234 ).

In terms of task-related activities, doing locum at government health facilities were associated with lower level of both acute fatigue (Adj. $b=-3.516,95 \%$ $\mathrm{CI}=-5.313$ to -1.719 ) and chronic fatigue (Adj. $b=-3.645$, $95 \% \mathrm{CI}=-5.703$ to -1.587 ) and higher level of recovery (Adj. $b=3.562,95 \% \mathrm{CI}=1.477$ to 5.647 ). However, doing locum at private health facilities was only associated with lower level of acute fatigue (Adj. $b=-1.684,95 \% \mathrm{CI}=-2.892$ to -0.476). As for work task, doing it at home was found to be associated with higher acute fatigue (Adj. $b=1.215,95 \%$ $\mathrm{CI}=0.107$ to 2.424 ) while doing it at workplace was associated with higher level of recovery (Adj. $b=1.651,95 \%$ $\mathrm{CI}=0.489$ to 2.812). Attending work-related training was also found to be associated with higher level of recovery (Adj. $b=1.704,95 \% \mathrm{CI}=0.235$ to 3.174 ).

As for work-related communication, virtual conversation with partner was associated with both higher acute fatigue (Adj. $b=1.395,95 \% \mathrm{CI}=0.212$ to 2.579 ) and lower recovery (Adj. $b=-2.270,95 \% \quad \mathrm{CI}=-3.611$ to -0.929 ). However, face-to-face conversation with partner was associated with higher level of recovery (Adj. $b=1.889,95 \%$ $\mathrm{CI}=0.543$ to 3.234 ).

\section{DISCUSSION}

Our study showed that participants generally experienced lower level of intershift recovery relative to their respective level of acute fatigue and chronic fatigue. Acute fatigue was moderately and positively correlated with chronic fatigue, and both were moderately and negatively correlated with levels of intershift recovery. Among the work-related activities done by participants during non-work time, workrelated ruminations were relatively more common and most of them were associated with poorer level of fatigue and recovery. The strength of our study is in the multiple dependant variables that simultaneously cover aspects of occupational fatigue and recovery, while the independent variables cover the rarely studied work-related activities during non-work time among doctors. However, this study findings cannot infer causation nor be generalised to non-doctor population. The use of self-reported questionnaires may raise issue of common-method bias despite the use of validated questionnaire to measure the dependant variables.

The moderate inter-correlations among acute fatigue, chronic fatigue and intershift recovery were in the expected direction. Previous studies also found similar results. ${ }^{6}{ }^{51}$ These are consistent with conceptualisation of fatigue and recovery which highlighted that acute fatigue may progress into chronic fatigue in the absence of sufficient recovery. ${ }^{1-6}$ These findings are also in line with COR theory that outline opposite concept of fatigue (ie, energy-depleted or loss state) and recovery (ie, energy-rich or gain state), ${ }^{7-9}$ and thus a negative correlation. In contrast, chronic fatigue is a consequence of accumulated unrecovered acute fatigue, and thus positive correlation. ${ }^{7-9}$ Similar moderate strength of inter-correlation among them may suggest the equal importance of intershift recovery for both types of fatigue. Therefore, a study of fatigue among doctors should consider including both types of fatigue as well as recovery if one wants a holistic intervention on fatigue. Nevertheless, as previously noted, correlation does not imply causation.

Work-related ruminations generally exert mental effort and consume energy resources ${ }^{7}$ that associated with poorer fatigue and recovery outcome. These are consistent with most of our findings on work-related ruminations. First, work-related rumination on being scolded or violated, which is not uncommon in healthcare setting, ${ }^{28-30}$ may cause psychological injury which requires a longer time to recover ${ }^{32}$ Previous study found that those involved in workplace violence were more likely to have chronic fatigue. ${ }^{33}$ Second, rumination on upcoming work may make it difficult to mentally disengage from work ${ }^{52}$ with the accumulation of acute fatigue into chronic fatigue. ${ }^{5}$ Alternatively, chronic fatigue may cause this rumination as it is associated with anxiety and low attentional control. ${ }^{53-55}$ Third, rumination on unfinished tasks may cause difficulty in disengaging from work, and hence poor recovery. ${ }^{56}$ Nevertheless, we found that rumination on patients/clients was associated with lower level of chronic fatigue, probably due to its positive nature ${ }^{57}$ arising from successfully treated patients. ${ }^{58}$ Contrariwise, it could be that those with chronic fatigue are less likely to ruminate on patients/clients as they are already in state of poor concentration and loss of motivation.

Task-related activities during non-work time, can happen at either home or workplace. In general, these types of activities exert physical and mental effort, and limits the time for recovery. However, all but one of our findings are opposite to this hypothesis. Doing work task at home was the only taskrelated activities that is associated with higher acute fatigue which probably causes failure to experience psychological detachment from work. ${ }^{22}$ In contrast, doing work task at workplace during non-work time was associated with higher recovery, which probably contributed by non-permeation 
of work-related demand into the home domain ${ }^{59}$ and avoidance of rumination on the unfinished task at home..$^{56061}$ Attending to work-related training during non-work time was also associated with higher recovery, which is possibly due to the benefit of knowledge gain that supports recovery through mastery experiences. ${ }^{62}$ In addition, doing locum at health facilities was associated with better outcome of fatigue and/or recovery. These are probably due to the motivation-driven effort or reward of financial gain that provides resilience to energy loss from work-related exertion ${ }^{6364}$ However, due to the cross-sectional design, it could be that those in a state of higher recovery or lower fatigue are those who are more likely to spend extra hour at work, attending work-related training or involve in a locum.

In terms of communication, we generally postulate that work-related conversation with partner generally enriches personal resources secondary to supportive social climate. ${ }^{8}$ However, it was found that physical conversation with partner did associate with higher recovery but virtual conversation with partner was associated with poor outcome of fatigue and recovery. These differential outcomes could be due to the presence of other unexamined confounders. ${ }^{65}$ Virtual means can be reached easily and immediately, thus fatigued doctors may likely express their work-related matter to their partners once finished their work such as during commuting home. Once at home, physical conversation with partner takes place in a more conducive environment that enhances recovery. However, this is just a speculation that require further study to look at the cause-effect relationship and examine other possible confounders.

Our study supports the growing concern about high levels of fatigue with low recovery among doctors, and the need to implement safe working hours legislation. However prescriptive traditional hour's rules have limited benefit ${ }^{66-68}$ and do not alone effective hazard control. ${ }^{66} 6970$ Fatigue risk management system (FRMS) with multiple levels of controls allow greater flexibility ${ }^{66}$ 71-73 through organisational policies and procedures. ${ }^{66} 74$ Therefore, we recommend a hybrid of prescriptive hours of service rule and FRMS health risk management approach ${ }^{66}$ that is locally-tailored to target population. First, a prescriptive schedule design. We propose health managers to implement a buffer zone schedule system for doctors to finish the unfinished task at workplace to avoid from bringing it home. For example, doctors who work until 17:00 hours should only be allowed to be on formal duty until 16:00hours. The remaining 1 hour buffer period should be spent on finishing the unfinished task at workplace. Second, a FRMS approach. It is a shared-responsibility approach that incorporates the risk assessment, mitigation, monitoring and review process. ${ }^{66}$ The health managers should be responsible to tackle the negative work-related rumination such as rumination on being violated at workplace at their root causes by providing safe and healthy work environment. ${ }^{66}$ In contrast, the doctors should be responsible for self-assessment of fatigue risk and disengage themselves from work during non-work time. They should also seek expert help in managing workrelated rumination that is associated with poor outcome of fatigue and recovery. Third, a written policy minimising the spillover of work-related demand into home domain should be developed. For instance, 'Right to Disconnect' law in France allow the workers to negotiate the conditions on the work after the working hours. ${ }^{75}$ It provides flexibility for organisations to deal with communication and taskrelated activities during non-work according to the FRMS approach.

Future studies should consider longitudinal design to allow causal inference among fatigue, recovery and workrelated activities during non-work time. A day-level study design should be considered to examine the day-level fluctuation of energy resources which denotes fatigue (energy loss) and recovery (energy gain). Finally, predictors or confounders at organisational and individual level such as use of work-related communication technology, motivation and rewards should be included in evidence to develop policy.

\section{CONCLUSION}

Participants generally experience higher level of acute and chronic fatigue as compared with intershift recovery, which are moderately correlated with each other and are associated with multiple work-related activities during non-work time. Work-related ruminations during nonwork time were common and mostly associated with poor fatigue and recovery outcomes while overt work activities done at workplace during non-work time were associated with better fatigue and recovery levels.

Acknowledgements The authors wish to thank Department of Community Health, Faculty of Medicine, Universiti Kebangsaan Malaysia and Selangor State Health Department in providing assistance in this study. We also thank the reviewers, namely Dr Peter Anthony Noone, Dr Tao Sun and Professor Dr Carel TJ Hulshof for the careful and insightful review of our manuscript.

Contributors MFMF, HMY and MRAM involve in conception and design of study. RMR, NAMS and MG involve in acquisition of data. MFMF, HMY and NAMS involve in data analysis and interpretation. MFMF, NAMS and MG involve in drafting the manuscript. HMY, MRAM and RMR involve in revising the manuscript critically for important intellectual content. All authors approved the final version of the manuscript to be published.

Funding This study is funded by Geran Peneraju Cabaran Perdana (GIP-2018-005) under Universiti Kebangsaan Malaysia. Universiti Kebangsaan Malaysia (National University of Malaysia) is a public-funded research university located in Malaysia. The funder has no role in the design of the research; in the collection, analyses or interpretation of data; in the writing of the manuscript, or in the decision to publish the results.

\section{Competing interests None declared.}

Patient consent for publication Not required.

Ethics approval This study is registered under National Medical Research Register (NMRR) (NMRR-19-1249-48464) and approved under Medical Research and Ethics Committee (KKM/NIHSEC/P19-1326(6)).

Provenance and peer review Not commissioned; externally peer reviewed.

Data availability statement Data are available upon reasonable request from the corresponding author

Open access This is an open access article distributed in accordance with the Creative Commons Attribution Non Commercial (CC BY-NC 4.0) license, which permits others to distribute, remix, adapt, build upon this work non-commercially, and license their derivative works on different terms, provided the original work is properly cited, appropriate credit is given, any changes made indicated, and the use is non-commercial. See: http://creativecommons.org/licenses/by-nc/4.0/. 
ORCID iD

Mohd Fadhli Mohd Fauzi http://orcid.org/0000-0002-6826-8391

\section{REFERENCES}

1 Phillips RO. A review of definitions of fatigue - and a step towards a whole definition. Transp Res Part F Traffic Psychol Behav 2015;29:48-56.

2 Patterson PD, Buysse DJ, Weaver MD, et al. Real-time fatigue reduction in emergency care clinicians: the SleepTrackTXT randomized trial. Am J Ind Med 2015;58:1098-113.

3 Meijman TF. Belasting en herstel: een begrippenkader voor arbeids-psychologisch onderzoek van werkbelasting [Effort and recuperation: a conceptual framework for psychological research of workload]. In: Meijman TF, ed. Mentale belasting en werkstress: een arbeidspsychologische benadering [Mental workload and job stress: a work psychological approach]. Assen/Maastricht: Van Gorcum, 1989: 5-20.

4 Beurskens AJ, Bültmann U, Kant I, et al. Fatigue among working people: validity of a questionnaire measure. Occup Environ Med 2000;57:353-7.

5 McEwen BS. Stressed or stressed out: what is the difference? J Psychiatry Neurosci 2005;30:315-8.

6 Winwood PC, Lushington K, Winefield AH. Further development and validation of the occupational fatigue exhaustion recovery (OFER) scale. J Occup Environ Med 2006;48:381-9.

7 Hobfoll SE. Conservation of resources. A new attempt at conceptualizing stress. Am Psychol 1989;44:513-24.

8 Hobfoll SE, Halbesleben J, Neveu J-P, et al. Conservation of resources in the organizational context: the reality of resources and their consequences. Annu Rev Organ Psychol Organ Behav 2018;5:103-28.

9 Hobfoll SE, Lilly RS. Resource conservation as a strategy for community psychology. J Community Psychol 1993;21:128-48.

10 Winwood PC, Lushington K. Disentangling the effects of psychological and physical work demands on sleep, recovery and maladaptive chronic stress outcomes within a large sample of Australian nurses. J Adv Nurs 2006;56:679-89.

11 Brown ID. Driver fatigue. Hum Factors 1994;36:298-314.

12 Arab AA, Khayyat HY. Risk of fatigue among anesthesia residents in Saudi Arabia. Saudi Med J 2017;38:292-6.

13 Cai S, Lin H, Hu X, et al. High fatigue and its associations with health and work related factors among female medical personnel at 54 hospitals in Zhuhai, China. Psychol Health Med 2018;23:304-16.

14 Ho J-C, Lee M-B, Chen R-Y, et al. Work-related fatigue among medical personnel in Taiwan. J Formos Med Assoc 2013;112:608-15.

15 McClelland L, Holland J, Lomas J-P, et al. A national survey of the effects of fatigue on trainees in anaesthesia in the UK. Anaesthesia 2017;72:1069-77.

16 McClelland L, Plunkett E, McCrossan R, et al. A national survey of out-of-hours working and fatigue in consultants in anaesthesia and paediatric intensive care in the UK and Ireland. Anaesthesia 2019;74:1509-23.

17 Tang C, Liu C, Fang P, et al. Work-related accumulated fatigue among doctors in tertiary hospitals: a cross-sectional survey in six provinces of China. Int J Environ Res Public Health 2019;16:3049.

18 Tucker PE, Cohen PA, Bulsara MK, et al. Fatigue and training of obstetrics and gynaecology trainees in Australia and New Zealand. Aust N Z J Obstet Gynaecol 2017;57:502-7.

19 Patterson PD, Buysse DJ, Weaver MD, et al. Recovery between work shifts among emergency medical services clinicians. Prehosp Emerg Care 2015;19:365-75.

20 BMA (British Medical Association). Fatigue and sleep deprivation the impact of different working patterns on doctors, 2018. Available: https://www.bma.org.uk/-/media/files/pdfs/collective\%20voice/ policy $\% 20$ research/education $\% 20$ and $\% 20$ training/fatigue-sleepdeprivation-briefing-jan2017.pdf?la=en [Accessed $30 \mathrm{Jul} 2019]$

21 Bihari S, Venkatapathy A, Prakash S, et al. ICU shift related effects on sleep, fatigue and alertness levels. Occup Med 2020;70:kqaa013

22 Sonnentag S, Bayer U-V. Switching off mentally: predictors and consequences of psychological detachment from work during off-job time. J Occup Health Psychol 2005;10:393-414.

23 de Jonge J, Shimazu A, Dollard M. Short-Term and long-term effects of Off-Job activities on recovery and sleep: a two-wave panel study among health care employees. Int $J$ Environ Res Public Health 2018;15:2044.

24 Querstret D, Cropley M. Exploring the relationship between workrelated rumination, sleep quality, and work-related fatigue. J Occup Health Psychol 2012;17:341-53.
25 Vandevala T, Pavey L, Chelidoni O, et al. Psychological rumination and recovery from work in intensive care professionals: associations with stress, burnout, depression and health. J Intensive Care 2017;5:16.

26 Niven K, Sprigg CA, Armitage CJ, et al. Ruminative thinking exacerbates the negative effects of workplace violence. $J$ Occup Organ Psychol 2013;86:67-84.

27 Van Laethem M, van Vianen AEM, Derks D. Daily fluctuations in smartphone use, psychological detachment, and work engagement: the role of workplace telepressure. Front Psychol 2018;9:9.

28 Behnam M, Tillotson RD, Davis SM, et al. Violence in the emergency department: a national survey of emergency medicine residents and attending physicians. J Emerg Med 2011;40:565-79.

29 Judy K, Veselik J. Workplace violence: a survey of paediatric residents. Occup Med 2009;59:472-5.

30 Zainal N, Rasdi I, Saliluddin SM. The risk factors of workplace violence among healthcare workers in public hospital. Mal J Med Health Sci 2018;14:120-7.

31 Lunardo R, Saintives C. Feeling a little guilt but ruminating a lot: how indulgence impacts guilt and its consequences. In: Kubacki $\mathrm{K}$, ed. Ideas in marketing: finding the new and polishing the old. developments in marketing science: proceedings of the academy of marketing science. Cham: Springer, 2015.

32 Coles J, Koritsas S, Boyle M, et al. GPs, violence and work performance - 'just part of the job?'. Aust Fam Physician 2007;36:189-91.

33 Li M, Shu Q, Huang $H$, et al. Associations of occupational stress, workplace violence, and organizational support on chronic fatigue syndrome among nurses. J Adv Nurs 2020;76:1151-61.

34 Zellars KL, Perrewé PL. Affective personality and the content of emotional social support: coping in organizations. J Appl Psychol 2001;86:459-67

35 Mellner C. After-hours availability expectations, work-related smartphone use during leisure, and psychological detachment: the moderating role of boundary control. Int $J$ Workplace Health Manag 2016:9:146-64.

36 Derks D, van Mierlo H, Schmitz EB. A diary study on work-related smartphone use, psychological detachment and exhaustion: examining the role of the perceived segmentation norm. J Occup Health Psychol 2014;19:74-84.

37 Barger LK, Cade BE, Ayas NT, et al. Extended work shifts and the risk of motor vehicle crashes among interns. N Engl J Med 2005;352:125-34.

38 Mohd Fadhli MF, Safian N, Robat RM, et al. Needlestick injury cases and adherence to the follow-up protocol among healthcare workers in Selangor. Malaysian J Pub Health Med 2018;18:55-63.

39 Motaarefi H, Mahmoudi H, Mohammadi E, et al. Factors associated with needlestick injuries in health care occupations: a systematic review. J Clin Diagn Res 2016;10:IE01-4.

40 Gates M, Wingert A, Featherstone R, et al. Impact of fatigue and insufficient sleep on physician and patient outcomes: a systematic review. BMJ Open 2018;8:e021967.

41 Landrigan CP, Rothschild JM, Cronin JW, et al. Effect of reducing interns' work hours on serious medical errors in intensive care units. N Engl J Med 2004;351:1838-48.

42 Tawfik DS, Profit J, Morgenthaler TI, et al. Physician burnout, wellbeing, and work unit safety grades in relationship to reported medical errors. Mayo Clinic Proceedings 2018;93:1571-80.

43 Gander P, Purnell H, Garden A, et al. Work patterns and fatigue-related risk among junior doctors. Occup Environ Med 2007;64:733-8

44 Linder JA, Doctor JN, Friedberg MW, et al. Time of day and the decision to prescribe antibiotics. JAMA Intern Med 2014;174:2029-31.

45 Medical Mythbusters Malaysia. Joint medical NGOs media statement for immediate release: perils of the Fatigued and sleep deprived doctor, 2017. Available: https://www.facebook.com/MedicalMythb ustersMalaysia/posts/1361891793901315:0 [Accessed 30 Jul 2019].

$46 \mathrm{MOH}$ (Ministry of Health Malaysia). Kenyataan Akhbar: Isu Kemalangan Jalan Raya di Kalangan Anggota Kesihatan. Ministry of health Malaysia: Malaysia, 2017. Available: https://kpkesihatan.com/ 2017/05/31/kenyataan-akhbar-kpk-31-5-2017-isu-kemalangan-jalanraya-di-kalangan-anggota-kesihatan [Accessed 30 Dec 2019].

47 AMA (Australian Medical Association). Hours of work, shiftwork and rostering for hospital doctors - AMA national code of practice, 2016. Available: https://ama.com.au/system/tdf/documents/FINAL_NCP_\% 20Hours_of_work_2016.pdf?file=1\&type=node\&id=37826 [Accessed 30 Dec 2019].

48 Abdul Rashid R. Malaysia health system research (MHSR) volume 1-contextual analysis of the Malaysian health system. Boston, Massachusetts: Harvard TH Chan School of Public Health, 2016. 
$49 \mathrm{MOH}$ (Ministry of Health Malaysia). Press statement director General of health Malaysia: on call claims by head of departments in hospitals. Malaysia: Ministry of Health Malaysia, 2015. https:// kpkesihatan.com/2015/03/24/on-call-claims-by-head-ofdepartments-in-hospitals

50 Park J, Kim Y, Chung HK, et al. Long working hours and subjective fatigue symptoms. Ind Health 2001;39:250-4.

51 Abdul Rahman H, Abdul-Mumin K, Naing L. Psychosocial factors, musculoskeletal disorders and work-related fatigue amongst nurses in Brunei: structural equation model approach. Int Emerg Nurs 2017:34:17-22.

52 Park Y, Fritz C, Jex SM. Relationships between work-home segmentation and psychological detachment from work: the role of communication technology use at home. J Occup Health Psychol 2011:16:457-67.

53 Janssens KAM, Zijlema WL, Joustra ML, et al. Mood and anxiety disorders in chronic fatigue syndrome, fibromyalgia, and irritable bowel syndrome: results from the lifelines cohort study. Psychosom Med 2015;77:449-57.

54 Joyce E, Blumenthal S, Wessely S. Memory, attention, and executive function in chronic fatigue syndrome. J Neurol Neurosurg Psychiatry 1996;60:495-503.

55 Moradi M, Fata L, Ahmadi Abhari A, et al. Comparing attentional control and intrusive thoughts in obsessive-compulsive disorder, generalized anxiety disorder and non clinical population. Iran J Psychiatry 2014;9:69-75.

56 Wright KB, Abendschein B, Wombacher K, et al. Work-related communication technology use outside of regular work hours and work life conflict: the influence of communication technologies on perceived work life conflict, burnout, job satisfaction, and turnover intentions. Manag Commun Q 2014;28:507-30.

57 Meier LL, Cho E, Dumani S. The effect of positive work reflection during leisure time on affective well-being: results from three diary studies. J Organ Behav 2016;37:255-78.

58 Frone MR. Relations of negative and positive work experiences to employee alcohol use: testing the intervening role of negative and positive work rumination. J Occup Health Psychol 2015;20:148-60.

59 Delanoeije J, Verbruggen M, Germeys L. Boundary role transitions: a day-to-day approach to explain the effects of home-based telework on work-to-home conflict and home-to-work conflict. Human Relations 2019;72:1843-68.
60 Zeigarnik B. On finished and unfinished tasks. In: Ellis WD, ed. $A$ source book of gestalt psychology. London, UK: Paul K, Trubner T \& Company, 1938: 300-14.

61 Ovsiankina M. Untersuchungen Zur Handlungs- und Affektpsychologie. Psychol Forsch 1928;11:302-79.

62 Sonnentag S, Fritz C. The recovery experience questionnaire: development and validation of a measure for assessing recuperation and unwinding from work. J Occup Health Psychol 2007;12:204-21.

63 Morgan P. Locum doctors. BMJ 1997;314:7074

64 Ohly S, Latour A. Work-Related smartphone use and well-being in the evening: the role of autonomous and controlled motivation. Journal of Personnel Psychology 2014;13:174-83.

65 McNamee R. Confounding and confounders. Occup Environ Med 2003;60:227-34.

66 Honn KA, VAN Dongen HPA, Dawson D. Working time society consensus statements: prescriptive rule sets and risk managementbased approaches for the management of fatigue-related risk in working time arrangements. Ind Health 2019;57:264-80.

67 Jones RA, Jimmieson NL, Griffiths A. The impact of organizational culture and reshaping capabilities on change implementation success: the mediating role of readiness for change. J Management Studies 2005;42:361-86

68 Sussman D, Coplen M. Fatigue and alertness in the United States railroad industry part I: the nature of the problem. Transp Res Part $F$ Traffic Psychol Behav 2000;3:211-20.

69 Dawson D, McCulloch K. Managing fatigue: it's about sleep. Sleep Med Rev 2005;9:365-80.

70 Darwent D, Dawson D, Paterson JL, et al. Managing fatigue: it really is about sleep. Accid Anal Prev 2015;82:20-6.

71 Cabon P, Deharvengt S, Grau JY, et al. Research and guidelines for implementing fatigue risk management systems for the French regional airlines. Accid Anal Prev 2012;45:41-4

72 Dawson D, Zee P. Work hours and reducing fatigue-related risk: good research vs good policy. JAMA 2005;294:1104-6.

73 Gander P, Hartley L, Powell D, et al. Fatigue risk management: organizational factors at the regulatory and industry/company level. Accid Anal Prev 2011;43:573-90.

74 Lerman SE, Eskin E, Flower DJ, et al. Fatigue risk management in the workplace. J Occup Environ Med 2012;54:231-58.

75 Mettling MB. Transformation numérique et vie au travail [Digital transformation and work life], 2015. Available: http://www.ladocume ntationfrancaise.fr/var/storage/rapports-publics/154000646.pdf [Accessed 30 Jul 2019]. 